\title{
Public Awareness of Mercury in Fish: Analysis of Public Awareness and Assessment of Fish Consumption in Vermont
}

\author{
William E. Damsky, Jr**, Elizabeth Duncan, Noreen Flanagan, Karen \\ Fromhold, Dung Hyunh, Russell Meyer, Jordan Sax, Thomas Delaney, \\ William Bress, Razelle Hoffman-Contois, and Jan K. Carney*
}

\begin{abstract}
Exposure to mercury from environmental sources, such as fish consumption, poses potential health risks to the public. The state of Vermont has developed educational brochures and posters displaying safe fish consumption guidelines in order to educate the public regarding mercury exposure through fish. In this study, a group of medical students from the University of Vermont College of Medicine, in partnership with the Vermont Department of Health, conducted a study in Chittenden County, Vermont in order to assess both fish consumption practices and overall awareness of such safe eating guidelines and mercury advisories. A total of 166 Vermont residents were surveyed during a six week period. The results of this survey suggest that in Chittenden county of Vermont, these educational efforts are markedly successful, with $48 \%$ of respondents being specifically aware of the safe eating guidelines. Further, these results suggest that $61 \%$ of those respondents that reported low monthly canned tuna consumption had a decreased their consumption in response to the safe eating guidelines. Last, a series of specific, yet widely applicable recommendations are presented for future public educational efforts regarding mercury exposure through fish consumption.
\end{abstract}

\section{INTRODUCTION}

Mercury exposure is a known public health risk. Exposure generally occurs through dental amalgams, vaccines, and/or fish consumption (1); this study will focus on the latter. Chronic mercury exposure in adults has been linked to both neurologic damage and cardiovascular disease (2). Mercury exposure is of special concern in women of childbearing age as mercury is a particularly potent neurotoxin during fetal development (3).

In response to several studies showing these adverse effects of mercury exposure, programs were launched in both the United States and Canada to provide safe eating guidelines for locally caught and commercial store-bought fish. Vermont is a state that has mobilized such educational efforts in the form of informational brochures and posters, one of which is

\footnotetext{
*To whom correspondence should be addressed: William E. Damsky

William.Damsky@uvm.edu (MD-PhD student) or

Jan K. Carney

Jan.Carney@uvm.edu (MD, MPH)
}

specifically targeted towards both pregnant and nonpregnant women of childbearing age. The advisories include charts organizing local and commercial fish by mercury content.

While the content of Vermont's fish advisory is presented simply and clearly, there is little data to determine whether the advisory is actually reaching Vermonters. Here, we report the results of a crosssectional analysis of 166 Vermonters aimed to assess fish consumption practices, estimate overall awareness of Vermont's safe-eating guidelines, and evaluate the effectiveness of these educational efforts.

\section{MATERIALS AND METHODS}

Surveying was conducted in person from September through December 2006 at five different locations in Chittenden County, Vermont (Table 1). Survey locations were selected specifically to achieve a geographically and socioeconomically diverse sample population. This population is probably quite representative of Chittenden county as a whole, but perhaps less representative of the entire state of Vermont. In total, 166 randomly selected men and women aged 18 and 
older were approached in person at the survey sites and asked to complete this retrospective survey that was developed by the authors specifically for this study. Respondents completed the survey privately at a table separate from the staff conducting the survey. The survey gathered demographic information, detailed fish consumption practices in an average month, evaluated awareness of Vermont's safe eating guidelines, and assessed fish-consumption changes (if any) participants may have enacted in response to these guidelines. One meal of fish was defined as an uncooked $8 \mathrm{oz}$. fillet or a $6 \mathrm{oz}$. can of tuna. Study methods were reviewed and accepted by the University of Vermont Institutional Review Board. Surveys were excluded if the demographic data was not completed or specific fish consumption practice questions were not completed or the answers were unclear.

Survey participants were stratified by gender, age, level of education, ethnic background, and whether or not participants had children less than six years of age. Women of childbearing age ( $18-44$ years old) were also considered separately. Chi-squared $(\chi 2)$ analysis was used to look for statistically significant differences in fish consumption practices between different groups of study subjects.

\section{RESULTS}

As shown in Table 1, 64\% of respondents were female (75\% of whom were of childbearing age). Sixty-one percent of respondents had at least some post-secondary education and $85 \%$ of respondents were Caucasian in ethnicity. Canned tuna was consumed most frequently, with $68 \%$ of respondents eating at least one meal per month. Nineteen percent reported eating Vermont caught fish at least once in an average month. Furthermore, individuals high in one category of fish consumption tended to be high in multiple categories.

Although $79 \%$ of respondents were aware of the adverse health effects of mercury in fish prior to the survey, only $48 \%$ were aware of specific Vermont safeeating guidelines. Of note, in the subset of participants that were both aware of the guidelines and ate fish, $67 \%$ reported at least some change in their fish-consumption practices in response to the guidelines.

$\chi 2$ analysis showed a statistically significant association $(p<0.025)$ between high education level (at least some post-secondary education) and reduced monthly tuna consumption (two or fewer meals per month). A difference in awareness of safe-eating guidelines was seen between subjects interviewed at the Burlington Library compared to those interviewed at the Department of Children and Families $(p<0.05)$. In women of childbearing age, there was an association between reduced level of canned tuna consumption and with both having seen a poster/brochure $(\mathrm{p}<0.05)$ and having specific knowledge of Vermont's safe-eating guidelines $(p<0.01)$. There was no association between fish consumption practices and whether or not the respondent had children less than six years of age.

\section{DISCUSSION}

Previous studies assessing fish consumption patterns in other states using a similar questionnaire have also measured hair mercury levels in a subset of subjects to estimate actual mercury exposure $(3,4)$. These studies have found a highly significant correlation between reported fish consumption and actual mercury levels in the body. These considerations suggest that the results of this study accurately reflect mercury exposure through fish consumption in this study population.

These data suggest that Vermont is successfully educating the public with regard to mercury exposure through fish consumption; $48 \%$ of those surveyed were aware of specific safe-eating guidelines. Compared to other states this awareness is rather high, for example similar studies in California, New Mexico, and North

\begin{tabular}{|c|c|c|c|}
\hline & $n$ & & $n$ \\
\hline Survey Site & & Aware of mercury in fish? & \\
\hline BPL: & 51 & Yes & 130 \\
\hline UP' & 16 & No & 34 \\
\hline DCF $^{\circ}$ & 34 & Undisclosed & 2 \\
\hline WIC & 15 & & \\
\hline \multirow[t]{2}{*}{$\mathrm{CHC}^{\circ}$} & 50 & Aware of VT guidelines? & \\
\hline & & $\begin{array}{l}\text { Yes } \\
\text { Yes }\end{array}$ & 78 \\
\hline Age & & No & 84 \\
\hline $18-44$ & 118 & Undisclosed & 4 \\
\hline 45 and over & 46 & & \\
\hline Undisclosed & 2 & Canned tuna consumption & 53 \\
\hline Gender & & One - two & 70 \\
\hline Male & 59 & Three - five & 32 \\
\hline Female & 105 & Five or more & 10 \\
\hline Undisclosed & 2 & Undisclosed & 1 \\
\hline Children $<6$ years old & & VT caught fish consumption & \\
\hline Yes & 49 & Zero & 129 \\
\hline No & 102 & One - two & 25 \\
\hline \multirow[t]{2}{*}{ Undisclosed } & 15 & Three - five & 4 \\
\hline & & Five or more & 1 \\
\hline Education & & Undisclosed & 7 \\
\hline Some high school & 20 & & \\
\hline High school degree & 45 & High mercury fish consumption' & \\
\hline Some college & 39 & Zero & 125 \\
\hline College degree & 39 & One - two & 29 \\
\hline Graduate degree & 23 & Three - five & 3 \\
\hline \multirow[t]{2}{*}{ Undisclosed } & 0 & Five or more & 4 \\
\hline & & Undisclosed & 5 \\
\hline \multicolumn{4}{|l|}{ Race/Ethnicity } \\
\hline American Indian & 4 & All other fish consumption & \\
\hline Asian & 7 & Zero & 62 \\
\hline African American & 5 & One - two & 62 \\
\hline Hispanic & 4 & Three - five & 30 \\
\hline Caucasian & 138 & Five or more & 10 \\
\hline Other & 5 & Undisclosed & 2 \\
\hline Undisclosed & 3 & & \\
\hline
\end{tabular}

Table 1: Demographic, fish consumption, and guideline awareness data. Data presented in this table has not been altered and includes surveys with some responses left blank. Fish consumption displayed as average servings per month. a) Burlington Public Library, Burlington, Vermont; b) University Pediatrics, Williston, Vermont; c) Department of Children and Families, Burlington, Vermont; d) Women, Infants, and Children (WIC), Burlington, Vermont; e) Community Health Center, Burlington, Vermont; f) species high in mercury defined as swordfish, shark, king mackerel, or tilefish. 
Carolina have reported awareness rates as low as $9 \%$, $9 \%$, and $10 \%$ respectively (3). A pooled analysis of guideline awareness data in eight states bordering the Great Lakes revealed $\sim 50 \%$ awareness (5), while Wisconsin reports a $77 \%$ awareness $(4,5)$. Furthermore, Vermonters are acting on this knowledge. Sixty-seven percent of those who had seen advisory posters/brochures reported changing their fish consumption practices as a result. A last observation was that Vermonters of lower education/income may not be as aware of the guidelines as Vermonters as a whole. This is evidenced, for example, by higher tuna consumption in the lower education level subset $(\mathrm{p}<0.05)$, though other explanations for this trend a certainly possible.

Study limitations included a large proportion of respondents: (a) with post-secondary education level, (b) reporting Caucasian ethnicity, and (c) living in Vermont's largest county. Additionally, the number of respondents in this study (166) is rather low, and a more extensive survey might reveal certain associations that this study was not able to identify. It would also be beneficial to assess advisory awareness throughout Vermont, focusing on more rural areas and populations with less educational attainment to see if awareness levels and fish consumption practices are similar.

\section{CONCLUSIONS}

This study suggests that current efforts to educate Vermonters about adverse health effects of mercury in fish are successful. Additionally, they might be further improved with additional emphasis on limits of fish consumption across all types of mercury-containing fish, not just those in individual categories. Based on these findings, the Vermont Department of Health has modified its public education materials. Although not addressed by this study, a final recommendation, based on recent work by Mahafferty et al. (6), would be to include information regarding omega-3 fatty acid content of different fish in addition to mercury levels. This will help the public make informed decisions by weighing the health benefits (omega-3 fatty acid content) versus the risks (mercury levels) in different species of fish.

\section{ACKNOWLEDGEMENTS}

Jan K. Carney MD, MPH is an author of a textbook and receives royalties relating to this publication: Carney, JK 2006. Public Health in Action. Jones and Bartlett Publishers.

\section{REFERENCES}

1. Clarkson, T.W., Magos, L., and Myers, G.J. (2003) The toxicology of mercury - current exposures and clinical manifestations. N. Engl. J. Med. 349, 1731 - 1737.

2. Clarkson, T.W. (2002) The three modern faces of mercury. Environ. Health Perspect. 110, Suppl. 1: 11-23.

3. Knobeloch, L., Anderson, H.A., Imm, P., Peters, D., and Smith, A. (2005) Fish consumption, advisory awareness, and hair mercury levels among women of childbearing age. Environ. Res. 97, $220-227$.

4. Knobeloch, L., Gliori, G., and Anderson, H. (2007) Assessment of methylmercury exposure in Wisconsin. Environ. Res. 103, $205-210$.

5. Imm, P., L. Knobeloch, H.A. Anderson, and the Great Lakes Sport Fish Consortium (2005) Fish consumption and advisory awareness in the Great Lakes Basin. Environ. Health. Perspect. 113: $1325-1329$.

6. Mahaffey, K.R., Clickner, R.P., and Jeffries, R.A. (2008) Methylmercury and omega-3fatty acids: Co-occurrence of dietary sources with emphasis on fish and shellfish. Environ. Res., 107: $20-29$.

William Damsky is a 5th year MD-PhD Student at the University of Vermont College of Medicine, Burlington, VT. Elizabeth Duncan MD, graduated from the University of Vermont College of Medicine in 2009. She is currently a firstyear resident in Pediatrics at Children's Hospital in Boston, MA.

Noreen Flanagan is a fourth year medical student at the University of Vermont College of Medicine, Burlington, VT. Karen Fromhold MD, graduated from the University of Vermont College of Medicine in 2009. She is currently a firstyear resident in Family Medicine at Fletcher Allen Health Care, Burlington, Vermont.

Dung Huynh is a fourth year medical student at the University of Vermont College of Medicine, Burlington, VT.

Russell Meyer MD, graduated from the University of Vermont College of Medicine in 2009. He is currently a medical intern and will subsequently begin a residency in Diagnostic Radiology at Fletcher Allen Health Care, Burlington, VT. Jordan Sax MD, graduated from the University of Vermont College of Medicine in 2009. He is currently a first-year Emergency Medicine resident at Johns Hopkins University Hospital in Baltimore, MD.

Thomas Delaney is a Research Associate in the Department of Pediatrics at the University of Vermont College of Medicine, Burlington, VT.

William Bress PhD, is the Vermont State Toxicologist, Vermont Department of Health, Burlington, VT.

Razelle Hoffman-Contois, MS, is the Risk Assessment Specialist with the Vermont Department of Health, Burlington, VT.

Jan K. Carney MD MPH, is the Associate Dean for Public Health at the University of Vermont College of Medicine, Burlington, VT. 